\title{
The Biological Approach to Psychiatry: History and Prospects
}

\author{
Samuel H. Barondes \\ Department of Psychiatry, Langley Porter Psychiatric Institute, University of California, San Francisco, \\ San Francisco, California 94143
}

\begin{abstract}
Medicine is becoming an increasingly molecular discipline, and in none of its specialities is this change causing more of a stir than in psychiatry. This is because psychiatry has been dominated, for many years, by subjective approaches to mental illness that are as far as one can get from quantitative science. No wonder psychiatrists have been unsettled by the realization that the next major advances in their field are bound to come from genetics and molecular hiology.

This article is written for neurobiologists who are becoming interested in this changing psychiatry. My goal is to put current developments into a historical perspective and especially to show that psychiatry already accommodates a biological approach. This approach became well established in the early part of this century as great advances were made in curing psychiatric disorders caused by readily discernible cellular pathology. At the same time psychoanalysis was invented to deal with problems that were not accompanied by obvious biological abnormalities. Eventually psychoanalysis so captured the imagination of both psychiatrists and the public that the biological approach came to be obscured. Now new developments in biology have set the stage for another change of emphasis.
\end{abstract}

\section{Causes of mental illness}

Since the primary concern of this article is mental illness, it is critical that we agree at the outset that such illness does exist. Although this proposition may seem self-evident, it remains a source of confusion or debate (Szasz, 1961). There is, for example, a reluctance to call someone mentally ill, inasmuch as the border between illness and normality is not well defined. There is also disagreement about whether "normal" means average or ideal. What is clear, however, is that there are patterns of behavior that are very uncomfortable for a person and for those with whom he or she interacts. And some patterns are so maladaptive that illness is obviously a proper designation.

A remarkable feature of mental illness is that it can come about in many different ways. These diverse origins have confused some people who were led to believe that behavioral abnormalitics must have psychological causes. Whereas psychological factors often do play a central role, many forms of psychiatric disorders have been shown to be due to overt brain pathology (Table 1).

\footnotetext{
Correspondence should be addressed to Samuel H. Barondes at the above address.
}

Copyright \& 1990 Society for Neuroscience $0270-6474 / 90 / 061707-04 \$ 02.00 / 0$
An example of a major psychiatric disorder with an overt brain pathology is dementia paralytica which, at the beginning of the twentieth century, affected about half the patients in psychiatric hospitals (Henry, 1941). It is a progressive mental illness that may begin with manic behavior and grandiosity, and progress to dementia and paralysis. Originally considered to be caused by psychological factors, it is actually a late manifestation of syphilis, with psychotic symptoms appearing only many years after the initial venereal infection. Once its etiology was established, antimicrobial agents provided a cure. The eradication of neurosyphilis is, therefore, a clear illustration of the value of the biological approach in psychiatry.

This frankly biological approach subsequently led to the elucidation of a number of other disorders with major psychiatric manifestations and with different types of etiologies (Table 1). Some disorders, such as myxedema, are due to hormonal deficiencies that can be corrected by replacement therapy. Others, like pellagra, are due to diets that lack sufficient vitamins and respond to nutritional treatment. Phenylketonuria is a genetic disorder that can be diagnosed on the basis of a simple biochemical test and that is treated by a dietary regimen based on an understanding of the primary cnzymatic abnormality.

The disorders listed in Table 1 are merely representative of a large number with prominent psychiatric features. They are all systemic diseases which may affect the function of many tissues, although their primary manifestations are often behavioral. Because they produce readily detectable gross or microscopic pathology, they could be analyzed by the biomedical technologies that developed in the first half of the twentieth century. It is, in fact, ironic that, since these disorders are so well understood, their historical importance for psychiatry is all but forgotten. But psychiatrists were also confronted with patients who suffered from the same types of psychological symptoms - such as depression, paralysis, and disordered thinkingbut who did not show any obvious biological pathology. This quandary set the stage for a radical change in psychiatric thought.

\section{Freud changes directions}

The ensuing movement away from an all-too-primitive biological explanation of psychiatric disorders to a direct attack on human psychology was led by Sigmund Freud. Despite his having been trained in neurobiology and neurology, Freud abandoned the biological approach because of its limited applicability to his patients. Instead, he boldly applied his rich psychological imagination to a wide range of human and psy- 
Table 1. Examples of medical causes of psychiatric disorders

\begin{tabular}{|c|c|c|c|}
\hline Disorder & $\begin{array}{l}\text { Major psychiatric } \\
\text { symptoms }\end{array}$ & Cause & Treatment \\
\hline Dementia paralytica & dementia, mania & $\begin{array}{l}\text { infectious (Treponema } \\
\text { pallidum) }\end{array}$ & penicillin \\
\hline Myxedema & depression & $\begin{array}{l}\text { hormonal (thyroid } \\
\text { hormone deficiency) }\end{array}$ & thyroxine \\
\hline Phenylketonuria & impaired intellect & $\begin{array}{l}\text { genetic (enzyme } \\
\text { deficiency) }\end{array}$ & $\begin{array}{l}\text { restrict } \\
\text { phenylalanine }\end{array}$ \\
\hline Pellagra & dementia, depression & $\begin{array}{l}\text { dietary (niacin } \\
\text { deficiency) }\end{array}$ & niacin \\
\hline
\end{tabular}

chiatric problems. To understand contemporary psychiatry, I believe that it is important to be aware of how this came about.

Freud's interest in neurobiology began as a medical student at the University of Vienna, where he worked with Ernst Brucke, a leading neuroanatomist and physiologist. During this period, rreud studied the histology of the spinal cord and ganglia of fish and published extensively in this area. He also made contributions to neuroembryology and to the development of techniques for tracing nerve fibers (Sulloway, 1979).

Freud then turned from basic research to neurology. To gain advanced clinical training he arranged for a fellowship with Charcot, the leading Parisian neurologist. It was Charcot who kindled Freud's interest in hysterical paralysis and its treatment by a psychological method, hypnosis. And it was probably this experience that made Freud consider psychology more seriously.

This new interest was further stimulated by his friend Josef Breucr, a physician who had also worked with Brucke. He too had excellent scientific credentials as the co-discoverer of the Hering-Breuer reflex, an early example of a neuronal feedback loop. But Breuer's most influential contribution was the successful treatment of Anna $O$., a patient with symptoms of hysterical paralysis, by an early form of long-term psychotherapy.

Freud's collaboration with Breuer on the psychological treatment of hysteria precipitated a personal crisis. On the one hand. Freud continued to view psychological phenomena from Brucke's perspective of their reducibility to the laws of biology and physics. On the other hand, Freud sensed that the behavior of his patients was ruled by different types of laws. A record of his struggle to reconcile these disparate perspectives is available in 2 notebooks that Freud filled during this period, which are included in his collected works as Project for a Scientific Psychology (Freud, 1895b).

This work, written in 1895 but published posthumously, begins with a very modern-sounding ambition: "The intention is to furnish a psychology that shall be a natural science: that is, to represent psychical processes as quantitatively determinate states of specifiable material particles, thus making those processes perspicuous and free from contradiction." The "specifiable material particles" were neurons; but it is clear from the notebooks that Freud could not formulate a practical strategy by which he could relate neuronal properties to clinical problems. Although he was full of ideas, they were not testable. So, after months of intense labor, he abandoned this effort. The reductionist physico-biological perspective and the criteria of scientific validation were replaced by a holist, psychological perspective and the criteria of textual interpretation.

In Studies on IIysteria ( $\Gamma$ reud, 1895a), which he publishcd with Breuer during this same year, Freud sought to explain this change. "I have not always been a psychotherapist. I ike other neuropathologists, I was trained to employ local diagnoses and electro-prognosis, and it still strikes me myself as strange that the case histories I write should read like short stories and that, as one might say, they lack the serious stamp of science. I must console myself with the reflection that the nature of the subject is evidently responsible for this, rather than any preference of my own. The fact is that local diagnosis and electrical reactions lead nowhere in the study of hysteria, whereas a detailed description of mental processes such as we are accustomed to find in the works of imaginative writers enables me, with the use of a few psychological formulas, to obtain at least some kind of insight into the course of that affection."

The upshot of Freud's struggle was the conclusion that, for the problems in which he had become interested, the biological approach was at least premature and possibly irrelevant. The judgement of prematurity was based on the limited power of contemporary biology to attack many of the problems of mental illness that Freud hoped to address. And, in subsequent writings, Freud indicated that he looked forward to the maturation of reductionist biology which would make it relevant to the matters that concerned him.

The regrettable thing about psychoanalysis is that it had great difficulty in advancing beyond its initial stage of tentative formulations. This is attributable to its failure to fashion testable hypotheses. And so, after almost a century, there remains very little in the psychoanalytic approach that can be proven to skeptics. Nevertheless, psychoanalysis has retained its appeal for precisely the reason that Freud invented it: it addresses psychiatric problems on the basis of a vision of human development and adaptation which, although unverificd, scems plausible. Biology, in contrast, had great difficulty in dealing with behavioral problems other than those caused by systemic illnesses with readily discernible pathologies. But in recent years the development of psychopharmacological treatments greatly increased biology's relevance.

\section{Drugs for mental illness}

Psychopharmacology originated as an enterprise in which drugs whose actions were not understood were used to treat psychiatric disorders whose causes were obscure. This was, after all, the pharmacological basis of all drugs of folk medicine. And for such major mental illnesses as schizophrenia and the affective disorders in which there are no obvious neuropathological concomitants to guide treatment, there seemed to be little else the psychiatrist could do for the patient. What made psychopharmacology so interesting was that once drugs that alleviated psychological symptoms were found, it became possible to attempt 
Table 2. A few drugs used in psychiatry

\begin{tabular}{|c|c|c|}
\hline Drug & Effect & Mechanism" \\
\hline Chlorpromazine & antipsychotic & $\begin{array}{l}\text { binds dopamine and other } \\
\text { receptors }\end{array}$ \\
\hline Reserpine & antipsychotic & blocks amine storage \\
\hline Imipramine & antidepressant & $\begin{array}{l}\text { blocks synaptic reuptake of } \\
\text { amines }\end{array}$ \\
\hline Tranylcypromine & antidepressant & blocks monamine oxidase \\
\hline Lithium & antimanic & $\begin{array}{l}\text { blocks phosphoinositide } \\
\text { metabolism }\end{array}$ \\
\hline Diazepam & antianxiety & hinds GABA, receptor \\
\hline
\end{tabular}

Many of these drugs bind to more than one brain protein and exert their effects in complex ways that involve multiple receptors, intermolecular interactions and long-term changes in the brain mediated by biological regulatory mechanisms clicited by their administration. Understanding of their mechanisms of action is, therefore, incomplete.

to infer the physiological cause of the illness from the mechanisms of action of the effective agents.

This approach was developed in the 1950s upon the introduction of several extremely valuable drugs whose usefulness was discovered largely by accident. For example, the phenothiazines, of which the antipsychotic chlorpromazine is an example, were originally developed as agents to help induce anesthesia. The antidepressant action of monamine oxidase inhibitors such as tranylcypromine was discovered by chance observation of the effects of a drug that was developed for treatment of tuberculosis. These discoveries led to a major scientific and pharmaceutic effort to develop better derivatives of these drugs and to determine the mechanisms of their therapeutic actions.

A few of the drugs commonly used to treat psychiatric disorders are listed in Table 2 (Cooper et al., 1982; Snyder, 1986; Meltzer, 1987). Even this short list serves to make the point that many types of substances, with different primary chemical actions, can specifically alter brain function. What these drugs have in common is their influence on synaptic neurotransmission. Some do this fairly directly by inhibition of neurotransmitter binding (e.g., chlorpromazine) or modulation of neurotransmitter binding (e.g., the antianxiety agent diazepam). Other drugs work by more indirect mechanisms. For example, the antidepressant imipramine inhibits the presynaptic reuptake of amine transmitters that normally terminates their action. The resulting accumulation of transmitter at the synapse then increases the duration of postsynaptic receptor activation. A similar accumulation of transmitter is achieved by blocking amine catabolism with the antidepressant monamine oxidase inhibitors. The antipsychotic reserpine, by contrast, acts by depletion of amines from presynaptic vesicular stores, which diminishes the amount of transmitter released by neuronal activity. Lithium, a potent antimanic agent, may act by influencing second messenger systems through its primary action on phosphoinositide metabolism (Berridge et al., 1989).

One of the most challenging problems of psychopharmacology is to explain how such alterations of neurotransmitter dynamics influence behavior. The task is complicated because a given neurotransmitter is often widely distributed in the nervous system and appears to participate in many neuronal circuits. Furthermore, therapeutic doses of some drugs, such as imipramine and lithium, that reduce pathological behavior, have little or no effect on normal behavior. Another complication is that the palliative behavioral effects frequently are not manifested for days or weeks after administering the drugs at their effective levels, indicating that an adaptive response to these agents, rather than their primary actions, is the critical therapeutic phenomenon. So further developments in psychopharmacology will depend, in part, on understanding how biological regulatory mechanisms in the brain produce sustained reactions to various perturbations of synaptic transmission, which may actually be responsible for the palliative psychological effects.

But, for the purposes of this article, the major point of Table 2 is that the development of psychopharmacology is already a vigorous activity in psychiatry. Although the imaginary stereotype of the psychiatrist is that of psychotherapist, the reality is that, for many years now, biological considerations have assumed ever-increasing psychiatric importance, as drugs have become more and more effective adjuncts to psychological treatment. And it is the increasingly biomechanistic orientation of psychopharmacology that has, in turn, helped to develop the cadre of psychiatrists who are prepared to participate in the current biological revolution.

\section{The promise of contemporary biology}

In the past decade there have been a number of developments in biology that are certain to impact directly on psychiatry. The 2 most important are advances in genetics and in the molecular biological studies of receptors. The former should lead to identification of the causes of some of the major mental illnesses that have seemed so mysterious because they are not associated with any obvious neuropathology. The latter should lead to development of more sophisticated and rational pharmacotherapies for psychiatric disorders, which will contribute not only to their palliation but also to an understanding of the pathogenesis of abnormal mental states.

The expected impact of genetics seems particularly exciting, since hereditary factors appear to play a major role in 2 major psychiatric disorders, schizophrenia and manic-depressive disorder (Nurnberger and Gershon, 1984; Egeland et al., 1987; Sherrington et al., 1988). Although evidence for a role of hereditary factors had been accumulating for decades, there seemed to be no way to identify the underlying genetic abnormality directly. The availability of new chromosomal mapping techniques now makes it possible to identify the responsible genes (Botstein et al., 1980; White and Caskey, 1988), as was recently done with the one responsible for cystic fibrosis (Rommens et al., 1989). Although the initially reported chromosomal localizations of genes responsible for manic-depressive disorder (Egeland et al., 1987) and schizophrenia (Sherrington et al., 1988) have been questioned (Byerley, 1989; Kelsoe et al., 1989), the genetic approach is bound to succeed ultimately. And it is likely that it will be extended to other conditions such as panic disorder and obsessive compulsive disorder for which a genetic predisposition is also indicated. Furthermore, genetic analysis of behavior may ultimately provide insights into conditions that are incompletely penetrant forms of major disorders, as well as reveal factors that predispose particular genotypes to certain temperaments. These advances might lead to a substantial change in our view of human nature.

The advent of techniques for cloning of cDNAs and genomic DNAs that encode neurotransmitter receptors has opened up a new approach to the design of specific drugs that interact with 
these proteins. One consequence of this development has been the identification of unsuspected receptor subtypes. A recent example is the discovery in the caudate nucleus of a second molecular form of $\mathrm{D}_{2}$ dopamine receptor that contains an insert of amino acid residues in the polypeptide domain believed to interact with $\mathrm{G}$ proteins (Chio et al., 1990). And since cloned receptor genes can be expressed after their transfection into cultured cell lines (Ashkenazi et al., 1989; Julius et al., 1990), a more precise pharmacological analysis of the receptors can now be carried out than was possible by studying them in whole animals, or even in identified neurons. In addition, examination of the regulatory regions of receptor genes will facilitate studies of the metabolic control of expression of individual neurotransmitter receptors. Such studies will help to elucidate those changes in concentration of receptor proteins in response to drugs which may be central to their therapeutic effects. Study of gene regulation also opens up the possibility of fathoming the mechanisms of tolerance and addiction to abused drugs, which are other important causes of mental illness.

The molecular biology of receptors will also permit many other types of advances. In situ hybridization studies with cDNAs encoding receptors, peptide neurotransmitters and enzymes involved in neurotransmitter biosynthesis are leading to the development of new types of maps of the brain. Such molecular maps will ultimately be correlated with the neuronal networks that control certain behaviors, such as the reward systems that are stimulated by certain drugs. Novel substances, such as transmitters, transporters, and molecules that participate in second messenger systems, continue to be discovered and characterized. All these findings should facilitate development of increasingly specific psychopharmacological agents. At the same time, disorders with overt neuropathologies such as AIDS and Alzheimer's disease will be better understood as a result of these general neurobiological advances.

These predictions follow directly from what has already been achieved in elucidating the biological causes of psychiatric disorders and in developing drugs for treatment. What may be less obvious is that the growing power of biology allows a rational approach to problems of brain organization that seemed hopelessly complicated only a few years ago. Because of the immense amount of information that is being added not only at the molecular and cellular levels but also at the systems level, we can actually contemplate transcending the view of the brain as an inscrutable "black box." There is, therefore, an excitement nowadays about the biological approach to psychiatry that was lacking in earlier times when there seemed to be no hope of truly understanding the mechanisms underlying the major behavioral disorders.

It is reasonable to expect that all this work will also have a great impact on those psychiatric problems that derive primarily from psychological or social factors. For example, management of symptoms attributable to causes of this type, such as some forms of anxiety and depression, should become more effective as we uncover the details of their specific neurobiological concomitants. The resultant control of psychological distress can do much to arrest the progression of such disorders in which initial symptoms, if untreated, can generate further deterioration.

There are, however, limits to the progress that one can expect from this approach. It is, for example, difficult to envision drugs that will undo the effects of maladaptive training, emotional deprivation, and child abuse. To cope with the resultant behavioral problems we must, therefore, continue to develop psychological techniques designed to reorient, clarify, and reeducate. And there is no substitute for the preventive measures that concerned citizens can bring about by their socially responsible activities.

But contemporary social and behavioral sciences appear to be as limited in addressing psychotherapy and psychoprophylaxis as the biology of Freud's time was in approaching the molecular genetics of mental illness. So the next revolution in psychiatry must await new ways of approaching behavior. Meanwhile, the psychiatrists and biologists who are committed to a molecular approach to mental illness can confidently look forward to some very productive years.

\section{References}

Ashkenazi A, Peralta EG, Winslow JW, Ramachandran J, Capon DJ (1989) Functionally distinct $G$ proteins selectively couple different receptors to PI hydrolysis in the same cell. Cell 56:487-493.

Berridge MJ, Downes CP, Hanley MR (1989) Neural and developmental actions of lithium: a unifying hypothesis. Cell 59:411-419.

Botstein D, White RL, Skolnick M, Davis RW (1980) Construction of a genetic linkage map in man using restriction fragment length polymorphisms. Am J Hum Genet 32:314-331.

Byerley WF (1989) Genetic linkage revisited. Nature 340:340-341.

Chio CL, Hess GF, Graham RS, Huff RM (1990) A second molecular form of $\mathrm{D}_{2}$ dopamine receptor in rat and bovine caudate nucleus. Nature 343:266-269.

Cooper JR, Bloom FE, Roth RH (1982) The biochemical basis of neuropharmacology. New York: Oxford UP.

Egeland JA, Gerhard DS, Pauls DL, Sussex JN, Kidd KK, Allen CR, Hostetter AM, Housman DE (1987) Bipolar affective disorders linked to DNA markers on chromosome 11. Nature 325:783-787.

Freud S (1895a) Case 5, Fraulein Elisabeth von R. Studies on hysteria. In: The standard edition of the complete psychological works of Sigmund Freud vol 2, p 160. London: Hogarth Press.

Freud S (1895b) Project for a scientific psychology. In: The standard edition of the complete psychological works of Sigmund Freud vol 1, p 295. London: Hogarth Press.

Henry GW (1941) Organic mental diseases. In: A history of medical psychology (Zilbourg GW, ed), pp 526-559, New York: WW Norton.

Julius D, Huang K, Livelli T, Axel R, Jessell T (1990) The 5HT, receptor defines a family of structurally distinct but functionally conserved serotonin receptors. Proc Natl Acad Sci USA 87:928-932.

Kelsoe JR, Ginns EI, Egeland JA, Gerhard DS, Goldstein AM, Bale SJ, Pauls DL, Long RT, Kidd KK, Conte G, Housman DE, Paul SM (1989) Re-evaluation of the linkage relationship between chromosome $11 \mathrm{p}$ loci and the gene for bipolar affective disorder in the Old Order Amish. Nature 342:238-243.

Meltzer HY (1987) Psychopharmacology. The third generation of progress. New York: Raven.

Nurnberger JI, Gershon ES (1984) In: Neurobiology of mood disorders (Post RM, Ballenger JC, eds), pp 76-101. Baltimore: Williams and Wilkins.

Rommens JM, Iannuzzi MC, Kerem B, Drumm ML, Melmer G, Dean M, Rosmahel R, Cole JL, Kennedy D, Hidaka N, Zsiga M, Buchwald M, Riordan JR, Tsui L, Collins FS (1989) Identification of the cystic fibrosis gene: chromosome walking and jumping. Science 245:10591065.

Sherrington R, Brynjolfsson J, Petursson H, Potter M, Dudleston K, Barraclough B, Wasmuth J, Dobbs M, Gurling H (1988) Localization of a susceptibility locus for schizophrenia on chromosome 5 . Nature 336:164-170.

Snyder SH (1986) Drugs and the brain. New York: Scientific American Books.

Sulloway FJ (1979) Freud, biologist of the mind. New York: Basic Books.

Szasz T (1961) The myth of mental illness. New York: Harper and Row.

White R, Caskey CT (1988) The human as an experimental system in molecular genetics. Science 240:1483-1488. 